\title{
AN ECOLOGICAL ANALYSIS OF QUALITY RATINGS AND INSPECTIONS ASSOCIATED WITH COVID-19 OUTBREAKS IN SKILLED NURSING HOMES
}

\author{
M.D. SIMON ${ }^{1}$, S.D. MESHKAT ${ }^{1}$, N. RAJA ${ }^{1,2}$ \\ 1. Office of Population Health and Accountable Care, UCLA Health System, Los Angeles, California. USA; 2. Division of Medicine, UCLA Health System, Los Angeles, California, \\ USA. Corresponding author: Megan D. Simon, 10960 Wilshire Blvd. Suite 1410, Los Angeles, CA 90024, mdsimon@mednet.ucla.edu
}

\begin{abstract}
Objectives: As COVID-19 spread across the United States, and most rapidly in skilled nursing homes, public health departments developed policies to mitigate the spread. Concerns grew over whether this spread linked to nursing home quality. Design: We collected data on nursing home quality, staffing, and COVID-19 cases from the Centers of Medicare and Medicaid Services. Demographic data was sourced from Long Term Care Focus. Settings and Participants: The analysis used cross-sectional data from 1,025 California skilled nursing homes including quality ratings and confirmed COVID-19 cases between May 17, 2020 and August 23, 2020. Methods: The dependent variable was confirmed COVID-19 cases among residents. The primary independent variables were Overall Rating and Health Inspection Rating, while also including nursing home beds, patient race composition, ownership and geographic classification. Results: 5-Star Overall Rating, 5-Star Health Inspection Rating, and a lower count of health inspection deficiencies each predicted a lower likelihood of having a confirmed COVID resident case $(\mathrm{p}<.05)$. Conclusions and Implications: Skilled nursing homes with higher quality ratings and fewer health inspection deficiencies were less likely to have a confirmed case of COVID-19 among residents.
\end{abstract}

Key words: COVID-19, nursing home, healthcare quality.

\section{Introduction}

A Center for Disease Control investigation in early March revealed how quickly SARs-CoV-2 spread in one Washington nursing home in King's County. After just a few weeks, the nursing home's index case infected an additional 167 employees, residents and visitors (1). Tracers found that this outbreak spread to eight more facilities and continued spreading across the county and beyond. This King's County nursing home had the highest possible CMS Star Rating for its region, and its outcome posed the question of how to prepare skilled nursing homes(NH) for the spread of a new, unknown virus.

\section{Links Between CMS Scores and Quality Outcomes}

Center for Medicare and Medicaid Services (CMS) Star Ratings come from a step-wise mix of scores on health inspections, quality, and staffing, before weighing the final score relative to performance in the state (2). The overall score is limited first by the health inspection rating, with the scores from the other components added thereafter. NHs with the top $10 \%$ of overall scores in each state receive a 5-star rating. High CMS Star Ratings significantly associate with improved quality outcomes including lower rates of emergency department visits, 30-day and 90-day readmissions, and mortality (3-5).

The components of the CMS Star Rating also demonstrate significant effects. Higher health inspection scores associate with a lower risk of 30-day readmissions and mortality (3, $6)$. Higher quality star ratings associate with a $20 \%$ reduction in ED visits (5). A meta-analysis of 150 studies determined that a higher ratio of nursing staff to patients is also linked to fewer health inspection deficiencies, lower readmissions and improved CMS clinical quality metrics (7).

Previous Factors Attributed to the Spread of COVID-19 in Skilled Nursing Homes

Key factors determined to influence the spread of COVID19 include a difficulty identifying individuals infected with COVID-19 based on signs and symptoms alone, industry trends in nursing home staff working at more than one facility, and location of a facility in a region with high community prevalence of the virus $(8,9)$.

Metropolitan regions have found that individuals of Black and Latinx race or ethnicity disproportionally make up more confirmed COVID-19 cases and deaths. A project within the San Francisco Mission District discovered that when testing was offered to all residents in the community, individuals identifying as Latinx represented $40 \%$ of those tested but $95 \%$ of confirmed cases (10). Risk factors listed include inability to shelter in place and maintain income, frontline service work, unemployment, and household income $<\$ 50,000$ a year. In May, a multi-state analysis revealed that $\mathrm{NHs}$ with a lower percentage of white residents, and a greater percentage of Black residents, are significantly more likely to have COVID-19 outbreaks (9).

While some studies found an inconsistent association between Overall CMS Star Rating and COVID-19 cases $(8,9)$, others found a significant link, including a study in California that analyzed cases reported between May 17th through June 2nd $(11,12)$. Since then, California Department of Public Health announced a new mandate for proactive facility-wide testing which had the effect of accelerating the identification 


\section{QUALITY RATINGS TIED TO COVID-19 IN NURSING HOMES}

of one or more cases. By looking at a longer time period, this study seeks to further understand the relationship between COVID-19 resident cases and quality ratings in California NHs. It also aims to determine whether health inspection findings associate with confirmed cases, while adjusting for $\mathrm{NH}$ size, ownership status and a higher percentage of white residents compared to California average.

\section{Methods}

Cross-sectional data was collected for 1,101 skilled nursing homes in California through CMS publicly-reported data and the Shaping Long Term Care in America Project. NHs were then selected for analysis based on availability of data for each of the variables.

\section{Data Collection}

COVID-19 case volume was reported by NHs from May 17 to August 23, 2020 to the CDC National Healthcare Safety Network and shared via the CMS Nursing Home COVID-19 Public File (13). Reporting of cases prior to May 17th, 2020 was deemed optional. NHs were categorized by those with one or more reported resident cases or no reported resident cases.

Patient demographic data was collected from the Shaping Long Term Care in America Project, supported by the National Institute on Aging and Brown University (14). Though the dataset's creation was several years ago, recent studies have used it to demonstrate significant association between skilled nursing home composition of race/ethnicity and presence of confirmed COVID-19 cases $(9,11,12)$. NHs were categorized into either above the California average percentage of white residents $(59.5 \%)$, or not above average.

$\mathrm{NH}$ metrics were extracted from the Centers of Disease Control to measure urban-rural classification, and from CMS Nursing Home Compare to measure bed count and ownership status (15). While previous studies found significance with occupancy rate (12), CMS data on NH occupancy showed declines each week reported, potentially confounding more SNFs reporting suspected or confirmed cases. To avoid selecting a confounding variable, we used CMS bed count.

CMS Nursing Home Compare also provided measures of quality, including Overall Star Rating, Staffing Star Rating, and Health Inspection Star Rating. To understand these measures more deeply, we also looked at count of health deficiencies by CMS-defined category, as well as average licensed practice nursing (LPN) hours per resident per day, which uses mandated payroll reporting and total residents at the $\mathrm{NH}$ to estimate the average. Since NHs are required to have a minimum of one registered nurse staffed at all hours, LPN staffing is more likely to vary independent of bed count (2). We used the Health Inspection rating as the primary independent variable as it has the greatest potential to impact a NH's overall rating (2).

\section{Statistical Analyses}

We measured significant relationships between the independent variables and confirmed COVID-19 cases using univariate logistic regressions. We then used multivariate logistic regressions to estimate the impact of the independent variables on cases while adjusting for size, ownership, above average white resident percentage and rural classification. Analyses were performed using R v 3.6.3. (R Core Team, 2020)

After analyzing the effect of Overall Star Rating, we looked at the rating components including Health Inspection Star Rating, and Staffing Star Rating. In order to understand the effect of specific deficiencies on cases, we used the three most common categories of Health Inspection deficiencies as defined by CMS: Quality of Life, Resident Rights and Resident Assessment and Care Planning deficiencies.

\section{Results}

We analyzed the results of 1,025 skilled nursing homes in California. Table I shows characteristics of NH by COVID-19 confirmed resident case volume and the resulting significance of independent logistic analyses. Each CMS quality or demographic variable showed a significant relationship to COVID-19 cases reported, with the exception of staffed LPN hours per patient per day.

To understand the relationship between Health Inspection Ratings and COVID-19 cases, we used a multivariate logistic regression. Table II summarizes the results of the first model which used Health Inspection Rating as the key independent variable. Health Inspection Rating showed a significant association to cases, while adjusting for beds, white resident percentage, ownership, and rural classification. The Odds Ratio of a 5-Star Rated NH having a case reported compared to a 1 -Star NH was 0.45 , suggesting these nursing homes are $45 \%$ less likely to have a confirmed case $(95 \%$ CI $0.25-0.80)$. For each additional bed, the odds of a confirmed case increased by $1.5 \%$ (OR 1.015, 95\% CI 1.01 - 1.02). NHs with above average percentage of white residents had a $57 \%$ lower likelihood of a confirmed case (OR $0.565,95 \%$ CI 0.42 - 0.75). For-profit ownership associated with a 70\% greater likelihood (OR 1.704, $95 \%$ CI $1.13-2.58)$. Lastly, nursing homes in rural areas had a $16 \%$ lower likelihood of a confirmed case (OR $0.162,95 \%$ CI $0.06-0.46)$. Using these variables, Figure I plots the model's predicted probability of each indexed nursing home to have a confirmed case. If the facility did have a case during the time period, they are marked in red while those without are marked in green.

Individual deficiencies also have a significant relationship with COVID-19 cases. Table III summarizes the results in this second model. Each quality deficiency associated with a $6.7 \%$ greater likelihood of a confirmed case (OR 1.067, 95\% CI $1.04-1.10)$ and each resident rights deficiency associated with an $8.1 \%$ greater likelihood (OR 1.081, 95\% CI $1.04-1.12$ ). Among the categories, care plan deficiencies had the largest 


\section{THE JOURNAL OF NURSING HOME RESEARCH SCIENCESC}

Table 1

Characteristics of Skilled Nursing Homes with COVID-19 Cases ( $\mathrm{n}=1025)$

\begin{tabular}{|c|c|c|c|c|}
\hline & 0 Cases & 1-10 Cases & $>10$ Cases & P Value \\
\hline Nursing Homes Reported by August 23, 2020 & 291 & 359 & 375 & \\
\hline Overall rating & & & & $<0.001$ \\
\hline 1 & $18(6.2 \%)$ & $31(8.6 \%)$ & $56(14.9 \%)$ & \\
\hline 2 & $33(11.3 \%)$ & $70(19.5 \%)$ & $88(23.5 \%)$ & \\
\hline 3 & $42(14.4 \%)$ & $70(19.5 \%)$ & $82(21.9 \%)$ & \\
\hline 4 & $61(21.0 \%)$ & $92(25.6 \%)$ & $65(17.3 \%)$ & \\
\hline 5 & $137(47.1 \%)$ & $96(26.7 \%)$ & $84(22.4 \%)$ & \\
\hline Health inspection rating & & & & $<0.001$ \\
\hline 1 & $39(13.4 \%)$ & $73(20.3 \%)$ & $101(26.9 \%)$ & \\
\hline 2 & $51(17.5 \%)$ & $89(24.8 \%)$ & $119(31.7 \%)$ & \\
\hline 3 & $69(23.7 \%)$ & $96(26.7 \%)$ & $67(17.9 \%)$ & \\
\hline 4 & $84(28.9 \%)$ & $79(22.0 \%)$ & $70(18.7 \%)$ & \\
\hline 5 & $48(16.5 \%)$ & $22(6.1 \%)$ & $18(4.8 \%)$ & \\
\hline \multicolumn{5}{|l|}{ Health inspection deficiency category } \\
\hline Quality of life & $5.8(5.6)$ & $9.2(6.1)$ & $11.1(7.5)$ & $<0.001$ \\
\hline Resident rights & $4.3(3.8)$ & $6.2(4.0)$ & $7.2(4.9)$ & $<0.001$ \\
\hline Resident assessment and care planning & $4.2(3.1)$ & $6.1(3.8)$ & $7.0(4.3)$ & $<0.001$ \\
\hline Staffing rating & & & & $<0.001$ \\
\hline 1 & $4(1.5 \%)$ & $6 \quad(1.8 \%)$ & $1 \quad(0.0 \%)$ & \\
\hline 2 & $51(19.2 \%)$ & $97(28.5 \%)$ & $157(44.0 \%)$ & \\
\hline 3 & $79(30.0 \%)$ & $145(42.6 \%)$ & $139(38.9 \%)$ & \\
\hline 4 & $87(32.7 \%)$ & $64(18.8 \%)$ & $48(13.4 \%)$ & \\
\hline 5 & $45(16.9 \%)$ & $28 \quad(8.2 \%)$ & $12(3.4 \%)$ & \\
\hline N/A & 25 & 19 & 18 & \\
\hline LPN staffing hours per resident per day & $1.17(0.43)$ & $1.13(0.45)$ & $1.1(0.37)$ & 0.0796 \\
\hline Beds & $79(39)$ & $103(45)$ & $120(64)$ & $<0.001$ \\
\hline White resident percentage & & & & $<0.001$ \\
\hline$>59.5 \%$ & $198(68.0 \%)$ & $186(51.8 \%)$ & $155(41.3 \%)$ & \\
\hline$<=59.5 \%$ & $93(32.0 \%)$ & $173(48.2 \%)$ & $220(58.7 \%)$ & \\
\hline Ownership & & & & $<0.001$ \\
\hline Non-Profit & $68(23.4 \%)$ & $52(14.5 \%)$ & $26(6.9 \%)$ & \\
\hline For Profit & $223(76.6 \%)$ & $307(85.5 \%)$ & $349(93.1 \%)$ & \\
\hline Geographic Classification & & & & $<0.001$ \\
\hline Urban & $268(26.9 \%)$ & $358(35.9 \%)$ & $371(37.2 \%)$ & \\
\hline Rural & $23(82.1 \%)$ & $1(3.6 \%)$ & $4(14.3 \%)$ & \\
\hline
\end{tabular}




\section{QUALITY RATINGS TIED TO COVID-19 IN NURSING HOMES}

effect size where each additional deficiency increased the likelihood of a confirmed case by $11.3 \%$ (OR $1.113,95 \%$ CI $1.07-1.16)$.

Table 2

Regression Results of Health Inspection Rating and COVID-19 Cases among California Skilled Nursing Homes

\begin{tabular}{|c|c|c|c|}
\hline \multirow[t]{3}{*}{ Covariates } & \multicolumn{3}{|c|}{ COVID-19 Cases } \\
\hline & \multirow[t]{2}{*}{ OR } & \multicolumn{2}{|c|}{$95 \%$ CI of OR } \\
\hline & & $\mathbf{L L}$ & UL \\
\hline \multicolumn{4}{|c|}{ Health inspection rating } \\
\hline 1 & Reference & & \\
\hline 2 & 1.169 & 0.752 & 1.818 \\
\hline 3 & 0.722 & 0.469 & 1.113 \\
\hline 4 & 0.733 & 0.473 & 1.138 \\
\hline 5 & $0.451 \dagger$ & 0.253 & 0.803 \\
\hline Beds & $1.015^{*}$ & 1.011 & 1.018 \\
\hline \multicolumn{4}{|c|}{ White resident percentage } \\
\hline$<=59.5 \%$ & Reference & & \\
\hline$>59.5 \%$ & $0.565^{*}$ & 0.423 & 0.754 \\
\hline \multicolumn{4}{|l|}{ Ownership } \\
\hline Non-Profit & Reference & & \\
\hline For Profit & $1.704 \div$ & 1.127 & 2.576 \\
\hline \multicolumn{4}{|c|}{ Geographic Classification } \\
\hline Urban & Reference & & \\
\hline Rural & $0.162 *$ & 0.057 & 0.461 \\
\hline
\end{tabular}

Table 3

Regression Results of Health Inspection Deficiency Category and COVID-19 Cases among California Skilled Nursing Homes

\begin{tabular}{|c|c|c|c|c|c|c|c|c|c|c|c|}
\hline \multirow[t]{3}{*}{ Covariates } & \multicolumn{11}{|c|}{ COVID-19 Cases } \\
\hline & \multicolumn{3}{|c|}{$95 \%$ CI of OR } & & \multicolumn{4}{|c|}{$95 \%$ CI of OR } & \multirow[b]{2}{*}{ OR } & \multicolumn{2}{|c|}{$95 \%$ CI of OR } \\
\hline & OR & $\mathbf{L L}$ & $\mathbf{U L}$ & & OR & $\mathbf{L L}$ & $\mathbf{U L}$ & & & $\mathbf{L L}$ & UL \\
\hline \multicolumn{12}{|c|}{ Deficiency Category } \\
\hline Quality & $1.067 *$ & 1.038 & 1.096 & $\begin{array}{l}\text { Resident } \\
\text { rights }\end{array}$ & $1.081 *$ & 1.039 & 1.124 & Care plan & $1.113^{*}$ & 1.066 & 1.162 \\
\hline Beds & $1.013^{*}$ & 1.010 & 1.017 & & $1.014 *$ & 1.010 & 1.018 & & $1.014 *$ & 1.010 & 1.018 \\
\hline \multicolumn{12}{|c|}{ White resident percentage } \\
\hline$<=59.5 \%$ & Reference & & & & & & & & & & \\
\hline$>59.5 \%$ & $0.605^{*}$ & 0.452 & 0.810 & & $0.555^{*}$ & 0.417 & 0.740 & & $0.551^{*}$ & 0.413 & 0.735 \\
\hline \multicolumn{12}{|l|}{ Ownership } \\
\hline Non-Profit & Reference & & & & & & & & & & \\
\hline For Profit & $1.570 \ddagger$ & 1.041 & 2.367 & & $1.634 \ddagger$ & 1.083 & 2.464 & & $1.610 \neq$ & 1.068 & 2.427 \\
\hline \multicolumn{12}{|c|}{ Geographic Classification } \\
\hline Urban & Reference & & & & & & & & & & \\
\hline Rural & $0.177 *$ & 0.062 & 0.503 & & $0.162 *$ & 0.057 & 0.463 & & $0.154 *$ & 0.052 & 0.455 \\
\hline
\end{tabular}

$* \mathrm{p}<.001, \dagger \mathrm{p}<.01, \ldots \mathrm{p}<.05 ; 1025$ cases
Figure 1

Graph of 1,025 Skilled Nursing Homes' Predicted Probability of a Confirmed Case of COVID-19 Among Residents

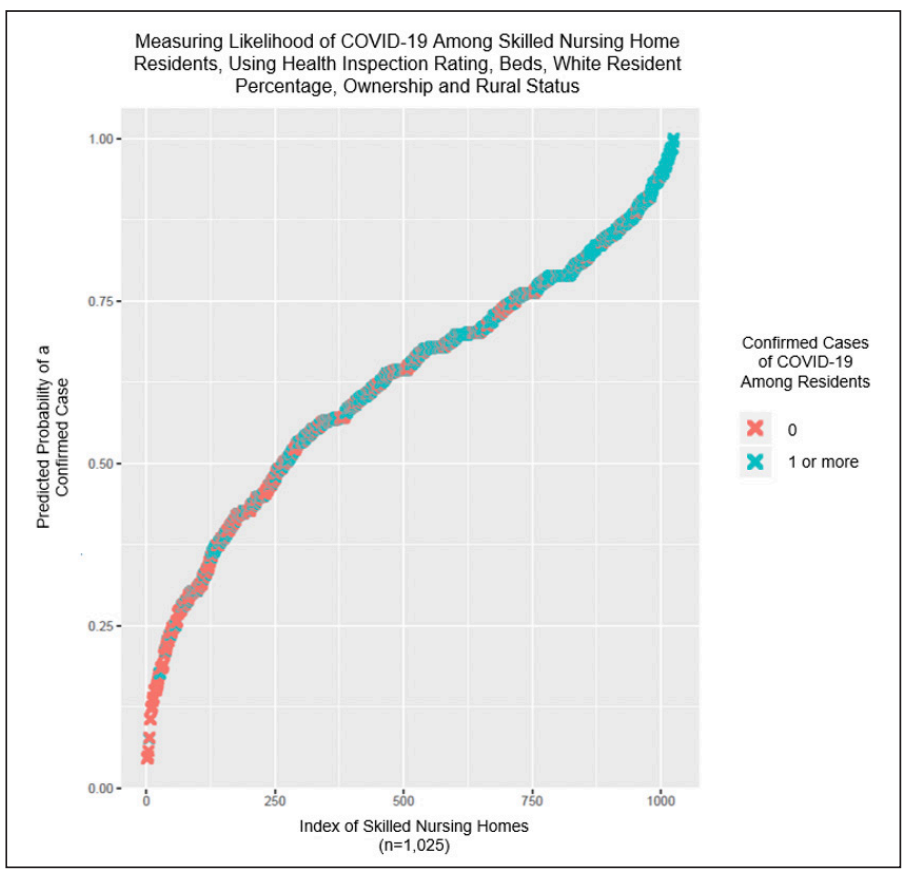

This graph plots each of the 1,025 nursing facilities against the model's prediction of a confirmed case. Facilities are marked with a red " $X$ " if the facility had 0 resident cases during the time period and a green " $\mathrm{X}$ " if the facility and 1 or more resident cases.

\section{Discussion}

This study shows a significant association between a number of important skilled nursing home quality metrics and the 


\section{THE JOURNAL OF NURSING HOME RESEARCH SCIENCESC}

likelihood of a confirmed COVID-19 case. The association remained after adjusting for influential $\mathrm{NH}$ demographics, including bed count, white resident percentage, ownership and rural classification. Figure I plots the model's success in predicting if a facility has a confirmed case. The model is relatively more accurate when a facility has a very low or very high probability predicted based on these variables.

Fewer quality, residents' rights or care plan deficiencies each associate with a lower likelihood of COVID-19 cases. These findings may answer current questions about the importance of CMS Health Inspections and also impact future policies and practices to support quality of care. Experts recommend increased oversight and regulation of nursing homes which contrasts with the CMS announcement in June 2020 to reduce frequency of inspections $(16,17)$. Further research and transparency is needed to understand the effect of these changes on patient care as well as how CMS identifies and categorizes health inspection deficiencies. In September 2020, CMS launched a new website, CareCompare, with less information about nursing home quality (17). Experts called for increased transparency on this website of quality ratings and enforcement of accurate ownership and financial information, which have proven ties to repeat quality issues (17). Our research shows that quality ratings and inspection findings have a meaningful association to the likelihood of an outbreak and are important data to share.

Because CMS Health Inspection Ratings may be weighted by the amount of time to respond to deficiencies and the relative performance of a nursing home compared to others in its state, a direct count of deficiency types may be more indicative of infection risk than ratings themselves (2). This study found significance with the three most common deficiency types. Future analyses should seek to understand the effect of other deficiency types on infection control.

While Staffing Rating demonstrated a significant association with the likelihood of a confirmed case $(\mathrm{p}<.001)$, other factors may limit this significance. These include recent changes in minimum staffing waivers and the relative movement of asymptomatic carriers (8). The intersection of quantity of staffing, quality of training and percentage of shared parttime staff with other NHs is of considerable interest for future studies.

Other factors beyond the scope of this study may contribute to the size of the outbreak, including amount of traffic in and out of NHs, air exchange rate and amount of physical space per resident $(1,8,10)$.

Additionally, education and supplies for infection prevention continue to be of importance in preventing the spread (1, $9,15)$. Patient-level factors, such as socioeconomic status, comorbidities or age, may also impact prevalence and presentation of the virus in NHs. More research is needed to capture and understand the relative effect of these factors in addition to quality ratings.

This study design is limited to NHs in only one state,
California. This state was selected in part because of its mandate for weekly facility testing and relative accuracy of mandated reporting. Still, the study is limited by the ability and willingness of NHs to test residents, and the true frequency of such tests. Due to this, the effect size may be underrepresented in this analysis.

This analysis does not suggest a causal link between health deficiencies and COVID-19 outbreak size. It looks to define the significance of quality ratings in relation to COVID-19 cases, which can highlight areas of opportunity for future outbreak management.

Skilled nursing homes with higher quality ratings and fewer health inspection deficiencies were less likely to have a confirmed case of COVID-19 among residents. By working to excel in these measures, while also following current COVID19 public health guidelines, skilled nursing homes may impact their performance on outbreak management of COVID-19 or other viruses.

Public policies to support ample staffing and adherence to infection prevention may also provide significant benefit. Some experts call for the reinstatement and expansion of a previous requirement for nursing homes to employ a parttime infection preventionist. CMS reduced this requirement in 2019 from infection preventionists employed "part-time" to "sufficient time" (19). Beginning January 1, 2021, California requires a full-time infection preventionist at all skilled nursing homes (20). Further research should evaluate the effect of this intervention and others on type and frequency of health inspection findings, quality of patient care, and overall prevention of the spread of infectious diseases.

Acknowledgements: We would like to thank the public health workers at the California Department of Public Health, Centers for Medicare and Medicaid Services, and LTCFocus for collecting this information and making it available to patients, family members and researchers.

Funding: The authors have declared no funding related to this article.

Conflict of Interest: The authors have declared no conflicts of interest.

Ethical standards: This study used data freely available in the public domain Therefore, the authors did not seek approval from an ethics body.

\section{References}

1. McMichael TM, Currie DW, Clark S, et al. Epidemiology of Covid-19 in a longterm care facility in King County, Washington. New England Journal of Medicine 2020;382(21):2005-2011.doi:10.1056/NEJMoa2005412 Published Online First: 21 May 2020.

2. Design for Nursing Home Compare Five-Star Quality Rating System: Technical User's Guide. The Centers of Medicare and Medicaid Services. 2020 Oct. https://www.cms.gov/Medicare/Provider-Enrollment-and-Certification/ CertificationandComplianc/Downloads/usersguide.pdf(accessed 1 Feb 2021).

3. Pandolfi MM, Wang Y, Spenard A, et al. Associations between nursing home performance and hospital 30-day readmissions for acute myocardial infarction, heart failure and pneumonia at the healthcare community level in the United States. Int J Older People Nurs 2017;12(4), e12154. doi:10.1111/opn.12154

4. Unroe KT, Greiner MA, Colón-Emeric C, et al. Associations between published quality ratings of skilled nursing facilities and outcomes of medicare beneficiaries with heart failure. J Am Med Dir Assoc. 2012;13(2):188.e1-188.e1886. doi:10.1016/j.jamda.2011.04.020 Published Online First: 31 May 2011.

5. Bartley MB, Rahman PA, Storlie CB, et al. Associations of SNF Quality Ratings With 30-Day Rehospitalizations and ED Visits. Ann Longterm Care. 2020;28(1):e11- 


\section{QUALITY RATINGS TIED TO COVID-19 IN NURSING HOMES}

e17. doi:10.25270/altc.2019.12.00091 Published Online First: 6 Dec 2019.

6. Neuman MD, Wirtalla C, Werner RM. Association Between Skilled Nursing Facility Quality Indicators and Hospital Readmissions. JAMA. 2014;312(15):1542-1551. doi:10.1001/jama.2014.13513. Published Online First 15 Oct 2014.

7. Harrington C, Schnelle JF, McGregor M, et al. The Need for Higher Minimum Staffing Standards in U.S. Nursing Homes. Health Serv Insights. 2016;9:13-19. doi:10.4137/HSI.S38994. Published Online First 12 Apr 2016.

8. Abrams HR, Loomer L, Gandhi A, et al. Characteristics of US Nursing Homes with COVID-19 Cases. J Am Geriatr Soc Published Online First: 2 Jun 2020. doi:10.1111/ jgs 16661

9. Testimony of R. Tamara Konetzka, PhD: Caring for Seniors amid the COVID19 Crisis. Special Committee on Aging, U.S. Senate. 116th Congress, 2nd Session 21st May (2020). https://www.aging.senate.gov/imo/media/doc/SCA Konetzka 05_21_20.pdf (accessed 1 Feb 2021).

10. Chamie G, Marquez C, Crawford E, et al. SARS-CoV-2 Community Transmission During Shelter-in-Place in San Francisco. medRxiv Published Online First: 17 Jun 2020. doi:10.1101/2020.06.15.20132233v1

11. Li Y, Temkin-Greener H, Shan G, Cai X. COVID-19 Infections and Deaths among Connecticut Nursing Home Residents: Facility Correlates. J Am Geriatr Soc. 2020;10.1111/jgs.16689. Published Online First 18 Jun 2020.

12. He M, Li Y, Fang F. Is There a Link between Nursing Home Reported Quality and COVID-19 Cases? Evidence from California Skilled Nursing Facilities. JAMDA Published Online First: 15 Jun 2020. doi:10.1016/j.jamda.2020.06.016.

13. CMS Nursing Home COVID-19 Public File. Centers for Medicare and Medicaid Services. https://data.cms.gov/provider-data/ (accessed 1 Feb 2021).
14. Brown University School of Public Health. LTCfocus: Long-term Care: Facts on Care in the US. 2018; http://ltcfocus.org/. (accessed 1 Feb 2021).

15. National Center for Health Statistics 2013Urban-Rural Classification Scheme for Counties. Centers for Disease Control and Prevention. 1 June 2017. https://www.cdc. gov/nchs/data_access/urban_rural.htm\#Data_Files_and_Documentation (accessed 5 April 2021).

16. Wang X, Ferro E, Zhou G, Hashimoto D, Bhatt D. Association Between Universal Masking in a Health Care System and SARS-CoV-2 Positivity Among Health Care Workers. JAMA Published Online First: 14 Jul 2020. doi:10.1001/jama.2020.12897.

17. Harrington C, Montgomery A, King T, et al. These Administrative Actions Would Improve Nursing Home Ownership and Financial Transparency in the Post COVID19 Period. Health Affairs. Published Online First: 11 Feb 2021. doi:10.1377/ hblog20210208.597573; (accessed 19 Feb 2021) https://www.healthaffairs.org/ do/10.1377/hblog20210208.597573/full/

18. Center for Clinical Standards and Quality/Quality, Safety, and Oversight Group "Posting of Nursing Home Inspections". CMS. 4 Jun 2020. (accessed 19 Feb 2021) https://www.cms.gov/files/document/qso-20-33-nh.pdf

19. Center for Medicare and Medicaid Services, Department of Health and Human Services. "Medicare \& Medicaid Programs; Requirements for Long-Term Care Facilities: Regulatory Provisions to Promote Efficiency and Transparency". Federal Register. CMS-3347-P. Section 483.80. 18 Jul 2019.

20. Assembly Bill No. 2644. SECTION 1. Section 1255.9 California Legislative Information. 30 Sep 2020. https://leginfo.legislature.ca.gov/faces/billTextClient. xhtml?bill_id=201920200AB2644 